\title{
Psychometric properties of the Valencia Scale of Attitudes and Beliefs Towards Hypnosis (client version) (VSABTH-C) online version
}

\author{
María Auxiliadora Franquelo ${ }^{1} \cdot$ Diogo Monteiro ${ }^{2}$ - Inés Tomás-Marco ${ }^{3} \cdot$ Antonio Capafons $^{4}$. \\ Antonio Hernández-Mendo 5
}

(C) Springer Science+Business Media, LLC, part of Springer Nature 2020

\begin{abstract}
The psychometric properties of the VSABTH-C have been previously analyzed in different studies. However, to the best of our knowledge, no study has ever tested the psychometric properties of the online version of VSABTH-C, considering the advantages that such administration represents: possibility of reaching a greater number of participants, speed of application and correction, and instantaneous feedback. In addition, previous studies have not conducted gender or time invariance. Thus, it is important to analyze the psychometric properties of this version, to confirm whether the model is optimal and can be used in other studies, and to confirm whether questionnaire provides unbiased scores to carry out comparisons across gender/time. The present study aim to analyze the psychometric properties of VSABTH-C, applied for the first time in its online version. Invariance analysis between gender/time was also analyzed in a total of 705 participants. Results from confirmatory factor analysis considering previous literature (eight factors 37 items) did not fit the data. An alternative model, removing six-items from the original model, was proposed. The re-specified model (eight factors 31 items) fit the data in all samples under analysis and revealed an adequate psychometric properties and shown invariance criteria between gender and time.
\end{abstract}

Keywords Hypnosis $\cdot$ Attitudes $\cdot$ Beliefs $\cdot$ Psychological assessment $\cdot$ Psychometric properties

\section{Introduction}

Hypnosis has been shown to have a large body of empirical evidence as a set of procedures to aid clinical intervention for the treatment of a wide range of medical and psychological disorders in children and adults (Mendoza \& Capafons, 2009). And there is ample

María Auxiliadora Franquelo

auxifranq@uma.es

1 Faculty of Psychology, University of Málaga, Málaga, Spain

2 Sport Science School of Rio Maior - Polytechnic Institute of Santarém, Research Center in Sport, Health and Human Development (CIDESD), Rio Maior, Portugal

3 Department of Behavioral Sciences Methodology, University of Valencia, Valencia, Spain

4 Department of Personality, Evaluation and Psychological Treatments, University of Valencia, Valencia, Spain

5 Department of Social Psychology, Social Work, Social Anthropology and East Asian Studies, University of Málaga, Málaga, Spain evidence of the improvement in the effectiveness and efficiency of the programs to which it is attached (Capafons, Morales, Espejo \& Cabañas, 2006), although the research methodology employed is not always the most appropriate (Molina del Peral, Mendoza, Capafons \& Llanes-Basulto, 2016). However, this improvement is mediated, in part, by the attitudes and beliefs of the people involved in the treatment, whether the client or the therapist (Capafons, 2012; Mendoza, Capafons \& Jensen, 2017; Spanos, Brett, Menary \& Cross, 1987).

It is often stated that attitudes and beliefs about hypnosis are important predictors of the hypnotic response, or in other words, how patients will respond to hypnotic suggestions (Green, Houts \& Capafons, 2012). Sociocognitive theories about hypnosis (Barber, 1969; Lynn \& Kirsch, 2004; Kirsch, 1991, 2000; Spanos \& Chaves, 1991) as the response set model or the response expectation model, state that expectations, beliefs, and motivation are critical determinants of a person's response to a suggestion. Furthermore, two clinical trials show that having positive attitudes at the beginning of 
the intervention is related to greater improvement in patients (Mendoza, Capafons \& Jensen, 2017).

On the other hand, beliefs, and attitudes directly influence the therapeutic relationship and rapport (Capafons, Alarcon, Cabañas \& Espejo, 2003). A person provided with correct information will have positive attitudes and appropriate expectations about what to expect from a hypnosis intervention, thus encouraging responses to hypnotic suggestions and adherence to treatment (Capafons, 2012; Spanos et al., 1987), contributing to increase the effects of the intervention, including the placebo effect (Sliwinskiand \& Elkins, 2013). Conversely, erroneous beliefs, negative attitudes, and inappropriate expectations about hypnosis are a risk factor, as they can generate iatrogenic effects (e.g., creating false memories or encouraging nocebo) (Capafons \& Mazzoni, 2005). Therefore, starting from a set of appropriate beliefs and positive attitudes is considered a determining factor in order to develop a safe and effective intervention programs (Capafons, 2012; Capafons \& Mazzoni, 2005). To do this, a correct evaluation of these beliefs and attitudes towards hypnosis should be started in order to avoid risks (Capafons et al., 2006). For all these reasons, many studies have been studying this issue (Green, 2003; Capafons et al., 2005; Capafons et al., 2006; McConkey, 1986; Spanos et al., 1987) and from them a set of measures are derived that are applied in interventions that include hypnosis.

Different studies carried out in Spain culminated in the formulation of the Valencia Model of Awakened Hypnosis (Alarcón \& Capafons, 2006; Capafons, 1999; Capafons \& Mendoza, 2010) and within the model emerged the Valencia Scale of Attitudes \& Beliefs Toward Hypnosis-Client Version (VSABTH-C) (Capafons et al., 2003; Capafons, Cabañas, Espejo \& Cardeña, 2004), also based on other existing scales (Keller, 1996). Initially, the Scale was made up of 28 items that were answered following a Likert scale from 1 to 5. The items were grouped into a total of six factors: Automaton, Help, Personal Control, Interest, Magic Solution and Collaboration, based on the exploratory studies carried out by Capafons et al. These studies (see Table 1), furthermore, proved a good internal consistency of the Scale and a high sensitivity to changes in beliefs and attitudes (Capafons et al., 2005; Capafons et al., 2006) and a confirmatory factor analysis found the proposed structure (Capafons et al., 2004). Subsequently, modifications were made, and a VSABTH-C was obtained with 37 items and a 6-point Likert response format. This modification was analyzed by Carvalho et al. (2007) in a Portuguese sample and revealed an eight-factor factor structure: Interest/ Attraction, Memory/Magic, Help, Control, Collaboration,
Marginal, Fear and Automata. This same version was used by Capafons et al. (2008) with translations into Portuguese, Romanian and English, and tested in a sample of Spain, Portugal, the United States and Romania. The results showed a factorial solution of eight factors: Help, Control, Magic, Interest, Collaboration, Fear, Memory/ Trance and Marginal. However, none of the studies show evidence of cultural invariance of Scale.

Subsequently, Green et al. (2012) analyzed the psychometric properties and factor structure of the Scale with North American students. The results, similar to those obtained previously, show a consistent and stable eight-factor factorial solution. This structure is replicated by Capafons et al. (2015) with a sample of university students with similar results, a factorial structure of eight factors: Fear, Memory, Help, Control, Collaboration, Interest, Magic, and Marginal. The results, as indicated, showed an optimal model fit. However, again no indicators are presented to test the invariance of this.

According to the above, studies proving the factor structures of VSABTH-C in different populations are found in the literature with satisfactory results. However, none of the studies prove that the psychometric properties remain constant across different groups (invariance of the models), a crucial aspect for the development and use of psychometric instruments (Cheung \& Rensvold, 2002; Sass, 2011). In regard to the invariance analysis, testing for gender and time invariance would contribute to the validation process of the VSABTH-C. First of all, significant gender differences in attitudes and beliefs towards hypnosis have been found in the literature (e.g., Capafons et al., 2008). Taking into account those results, it seems reasonable that future research could be interested in testing gender differences in attitudes and beliefs towards hypnosis. Factorial invariance analyses would provide an indication of whether or not statistically significant differences based on scale scores would reflect real differences across gender groups in the underlying latent variables measured by the VSABTH-C.

A similar logic underlies the relevance of carrying out time invariance analysis. Researchers could be interested in analyzing whether or not attitudes and beliefs towards hypnosis fluctuate across time (Capafons et al., 2005). However, comparisons among times are meaningful only when invariance across time has been empirically shown. Thus, time factorial invariance would provide an indication of whether or not statistically significant differences based on scale scores would reflect real differences across time groups in the underlying latent factors measured by the VSABTH-C. Testing measurement invariance of the scale across time would provide further support for the use of the VSABTH-C 
in testing changes in attitudes and beliefs towards hypnosis across time, and the unbiased comparison of average scores across time.

Taking into consideration all of the above, the aim of present study were: (1) analyze the factor structure of VSABTH-C in its online version (being the first time that the Scale is applied in online mode), starting from the exploratory and confirmatory analyses carried out so far; (2) analyze the internal consistency, convergent validity and discriminant validity; and (3) analyze the invariance of the measurement model across time and gender, since so far, no study has presented this analysis and this would contribute to the advancement of the field of knowledge, providing the necessary evidence to constitute a valid, reliable and changesensitive online tool.

\section{Method}

\section{Participants}

A total of 705 participants, aged between 18 and 58, were enrolled in this study $(M=22.73 S D=5.78)$, fourth-grade students in Psychology bachelor of University, as well as participants of a university extension course in hypnosis. The sample was split by gender (242 male; 463 female). Likewise, with respect to the time at which it was carried out, it was divided into those who responded only once to the Scale ( $n=261$ ) (independent), with 169 female and 92 male; and the remaining participants ( $n=444 ; 294$ female; 150 male) who responded twice to the Scale (moment 1 and 2). The inclusion criterion was subjects with 18 years old and over. For more details, see Fig. 1.

With respect to previous experience with hypnosis, $15 \%$ of the participants had had direct experience or had received science-based training or education; and $62 \%$ had received some kind of information (television and non-scientific journals).

\section{Instruments}

The Valencia Scale of Attitudes and Beliefs Toward Hypnosis-Client Version (Capafons et al., 2015) was used in its online version of 37 items in Spanish. In addition to the items, the VSABTH-C includes a preliminary questionnaire where information is collected regarding the participants' previous experience with hypnosis (if they have ever been hypnotized and by whom, if so; as well as whether they have received any previous information and from what source).

\section{Procedure}

The administration of the instrument was carried out through the Menpas online Psychosocial Evaluation platform (González-Ruíz, Domínguez-Alfonso, ChicaMerino, Pastrana-Brincones \& Hernández-Mendo, 2018; González-Ruíz, Hernández-Mendo \& PastranaBrincones, 2010), during the years 2018 and 2019. Time between survey administrations for moment 1 and 2 was eight months. In order to complete the Scale online, participants, having an internet connection,

Fig. 1 Study design

705

participants divided by

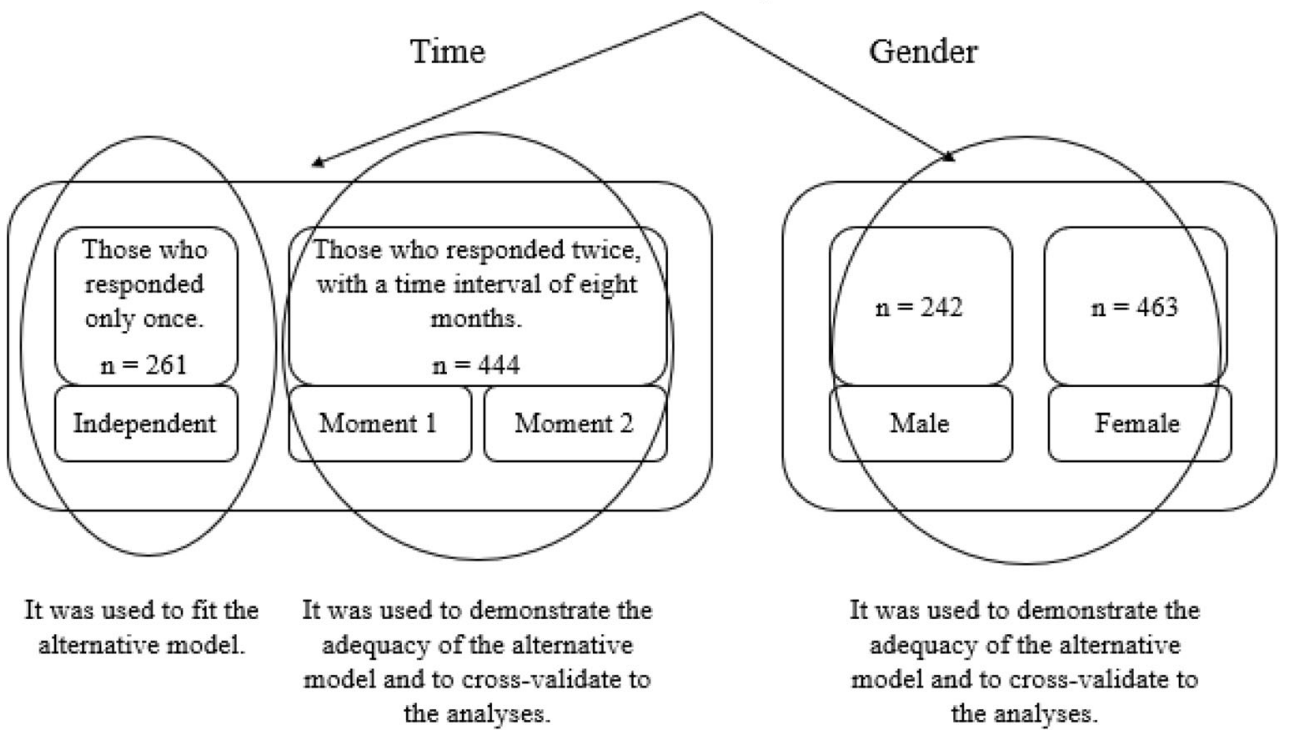


had to register on the platform, previously filling in a form with socio-demographic data to then answer the Scale. Not all of these sociodemographic data (nationality, gender, age, marital status, profession, level of studies, sport practiced and weekly hours of sport practice, and year of start) were relevant or used for the study, but they helped to obtain a general idea about the sample and to have data that could lead to future research. After eight months participants were asked to complete the Scale again, accessing the platform each with their personal account. Access to the application and the handling of the information collected, including the results of the Scale without personal information, could only be done by the application manager (one of the authors of the study). The ethical principles of the Declaration of Helsinki (World Medical Association, 2013) were also respected throughout the research process.

\section{Statistical Analysis}

Descriptive statistics, including mean and standard deviation were calculated for the variables included in the study (responses given by the participants to each of the items). Subsequently, a Confirmatory Factor Analysis (CFA) was performed to test the factor structure of the questionnaire, using a 5:1 ratio, to calculate the number of participants needed based on the parameters to be estimated (Worthington \& Whittaker, 2006). Maximum likelihood (ML), via AMOS 23.0 was used as the estimation method, following recommendations of several authors (e.g. Byrne, 2010; Hair, Black, Babin \& Anderson, 2014; Kline, 2011; Worthington \& Whittaker, 2006). Beyond Chi-square $\left(\chi^{2}\right)$, degrees of freedom $(d f)$ and level of significance, the following goodness-of.fit indexes were considered to evaluate the model fit: Comparative Fit Index (CFI), Tucker-Lewis Index (TLI), Root Mean Square Error of Approximation (RMSEA) with its confidence interval (90\% CI), and Standardized-Root Mean SquareResidual (SRMR). The cut-off points adopted for each index were CFI and TLI $\geq .90$ and RMSEA and SRMR $\leq .08$ (Byrne, 2010; Hair et al., 2014; Marsh, Hau \& Wen, 2004). Convergent validity was also examined based on the average variance extracted (AVE), taking the AVE cut-off point $\geq .50$ (Hair et al., 2014). Discriminant validity was determined to the extent that the AVE of each latent variable was greater than the square of the correlation between them (Hair et al., 2014). The internal consistency was calculated using Cronbach's Alpha $(\alpha)$ (Cronbach, 1951), as well as from the composite reliability, taking .70 as the cut-off point (Hair et al., 2014).

\section{Invariance Analysis}

Invariance analysis enables assessment of the equivalence of the measurement model between groups with different characteristics (Sass, 2011). In addition, according to several authors (e.g., Byrne, 2010; Chen, 2007; Kline, 2016; Sass, 2011), invariance analysis is the pre-requisite to further conduct other comparisons analysis, such as latent mean differences (Meredith, 1993). In line with that, the invariance analysis was performed to determine whether the re-specified model could be replicated in different groups. According to Byrne (2010) and Cheung \& Rensvold (2002), two aspects must be fulfilled to this end: (1) the model must be adjusted for each group; (2) different levels of invariance must be examined: configural invariance, implies that the same item is associated with the same factor for each group; metric invariance, implies that the items present invariant factor saturations across the groups compared, and is required to compare pending regression or changes in scores in longitudinal studies; scalar invariance, implies that both factor saturations and intercepts are invariant, and its compliance indicates that the scores of the different groups have the same unit of measurement and the same origin; and residual invariance, implies that both factor saturations and intercepts and residuals are invariant, and its compliance represents that the group differences in the items are only due to differences in the factors (Chen, 2007). As indicated by Chen (2007), changes of less than $\leq$ .01 in CFI $(\triangle \mathrm{CFI})$, changes of less than $\leq .015$ in RMSEA ( $\triangle$ RMSEA) and changes of less than $\leq .030$ in SRMR $(\triangle$ SRMR) would reflect virtually irrelevant differences between the groups. Similar procedures have been used by several authors (e.g., Stenling, Ivarsson, Lindwall \& Gucciardi, 2018; Rodrigues et al., 2019). The analysis was conducted in AMOS 23.0.

\section{Results}

\section{Preliminary Analysis}

A preliminary analysis of the data showed that there were no missing values. However, six multivariate outliers were identified in the sample of moment 1 (Mahalanobis distance $=p_{1}<.001 ; p_{2}<.001$ ) that were eliminated for the following analyses, as suggested by Byrne (2010). The remaining samples (moment 2 and independent sample) no multivariate outliers were identified. Additionally, no problems of univariate normal distribution were verified in all samples (moment 1 , moment 2 and independent sample), since the values 
of skewness and kurtosis varied between -2 and +2 and between -7 and +7 , respectively (Byrne, 2010). However, the multivariate kurtosis coefficient of Mardia showed a violation of the multivariate distribution in all samples (values >5.0). Therefore, a Bootstrap Bollen - Stine of 2000 samples was performed, as suggested by Nevitt \& Hancock (2001).

\section{Confirmatory Factor Analysis}

The independent sample (i.e., participants who only responded once of the scale), was used to analyze all models from previous studies (exploratory model by Carvalho et al. (2007) with eight factors and 37 items; confirmatory model by Capafons et al. (2008), with eight factors and 37 items; model by Green et al. (2012), with eight factors and 37 items; and confirmatory model by Capafons et al. (2015), with eight factors and 37 items). However, as shown in Table 1, all of them did not fit the data well (Byrne, 2010; Hair et al., 2014; Marsh, Hau \& Wen, 2004). Therefore, an alternative model was analyzed to meet the theoretical integrity, parsimony and fit of the data (Kline, 2011). Based on the results of Capafons et al. (2015), the items were examined individually, and the model was readjusted by eliminating six items from the VSABTH-C (item 4: "hypnosis scares me", and item 16: "hypnosis is a safe technique, with few risks", from the Fear factor; item 11: "the hypnotized person is passive", from the Marginal factor (eliminated also in the starting model (Capafons et al., 2015), which was included in the present analysis with the intention of finding out if their behavior was replicated); item 22: "under hypnosis they can force the person to do things they don't want to do", of the Control factor; and items 17 y 29: "hypnosis promotes the capacity for selfcontrol" and "one learns faster under hypnosis", of the Help factor, respectively). These items were removed, since they were considered crossloadings (i.e., high correlations values with different factors of the scale). Thus, according to several authors (e.g., Kline, 2016; Hair et al., 2014; Worthington and Whittaker, 2006) when there are several crossloadings it is prudent to consider the elimination of some items. After removing the aforementioned items, a CFA of the eight factors/31-items scale showed good fit for the eight defined factors assessing attitudes and beliefs toward hypnosis.

Thus, the alternative final model, with eight factors and 31 items, revealed a good fit to the data in all samples under analysis (independent sample, male and female samples, as well as both in moment 1 and 2), as shown in Table 1, and Figs. 2 and 3.

\section{Descriptive Statistics, Internal Consistency, Convergent Validity and Discriminant Validity}

Table 2 shows the descriptive analyses of the items that are part of the final version of the Scale, it can be seen that most of the responses ranged between 1.85 ( $S D=$

Table 1 Goodness-of-fit ratings of the previous and alternative VSABTH-C models.

\begin{tabular}{|c|c|c|c|c|c|c|c|c|c|c|}
\hline Model & & $x^{2}$ & $\mathrm{df}$ & $\chi^{2} / \mathrm{df}$ & B-S p & SRMR & CFI & TLI & RMSEA & $90 \% \mathrm{CI}$ \\
\hline \multicolumn{11}{|l|}{ Previous models } \\
\hline \multirow[t]{2}{*}{ Carvalho et al. (2007) } & Values obtained & 1931.90 & 532 & 3.63 & $<.001$ & .09 & .82 & .84 & .08 & $.07-.08$ \\
\hline & Values reported by the authors & 1714.07 & 601 & - & - & .10 & .95 & - & .06 & - \\
\hline \multirow[t]{2}{*}{ Capafons et al. (2008) } & Values obtained & 2266.77 & 467 & 3.83 & $<.001$ & .08 & .79 & .76 & .09 & $.07-.08$ \\
\hline & Values reported by the authors & 2009.02 & 602 & - & - & .13 & .94 & - & .07 & - \\
\hline \multirow[t]{2}{*}{ Green et al. (2012) } & Values obtained & 2170.41 & 566 & 3.83 & $<.001$ & .11 & .82 & .80 & .08 & $.07-.08$ \\
\hline & Values reported by the authors & 1500.10 & 566 & - & - & .10 & .96 & - & .06 & - \\
\hline \multirow[t]{2}{*}{ Capafons et al. (2015) } & Values obtained & 1983.43 & 566 & 3.50 & $<.001$ & .09 & .84 & .82 & .07 & $.07-.08$ \\
\hline & Values reported by the authors & 2972.02 & 566 & - & - & .08 & .95 & - & .05 & - \\
\hline \multicolumn{11}{|l|}{ Alternative model } \\
\hline Moment 1 & Values obtained & 1113.46 & 406 & 2.74 & $<.001$ & .07 & .91 & .90 & .06 & $.05-.06$ \\
\hline Moment 2 & & 1022.12 & 406 & 2.52 & $<.001$ & .06 & .92 & .91 & .06 & $.05-.06$ \\
\hline Independent & & 1284.49 & 406 & 3.16 & $<.001$ & .05 & .93 & .92 & .06 & $.05-.06$ \\
\hline Female & & 976.32 & 406 & 2.40 & $<.001$ & .06 & .92 & .91 & .05 & $.05-.07$ \\
\hline Male & & 846.34 & 406 & 2.08 & $<.001$ & .06 & .90 & .90 & .07 & $.06-.07$ \\
\hline
\end{tabular}

Note $-=$ value not provided by the authors; $\chi^{2}=$ chi - square; $\mathrm{df}=$ degrees of freedom; $\chi^{2} / \mathrm{df}=$ chi - normalized square; B-S $\mathrm{p}=\mathrm{Bollen}$ - Stine Bootstrap significance level (2000) samples; SRMR = standardized root mean square residual; $\mathrm{CFI}=$ comparative fit index; TLI = Tucker-Lewis Index; RMSEA = root mean square error of approximation; $\mathrm{CI}=$ confidence interval. 


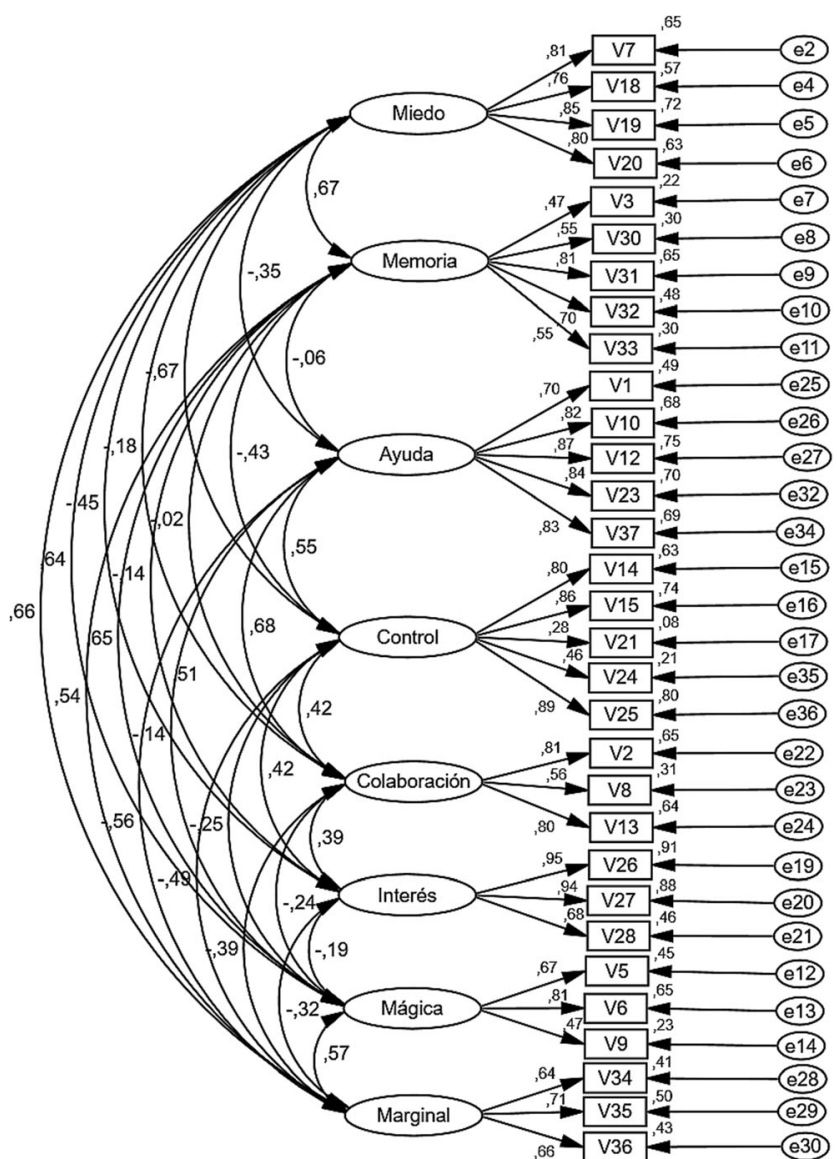

Fig. 2 Standardized individual parameters of the VSABTH-C for the sample at moment 1 (left)

1.17) (item 6) and $4.97(S D=1.18)$ (item 37) for the sample at the first moment in time; and between 1.95 $(S D=1.22)$ (item 6) and $5.28(S D=.91)$ (item 2) for the sample at the second moment in time.

Similarly, as shown in Table 3 and based on the strategies mentioned in the procedure, some factors present convergent validity values lower than those recommended (AVE $\geq .50)$. These are, Memory (.39), Magic (.44) and Marginal (.45) in the first temporal moment; and Memory (.42), Magic (.41) and Marginal (.41), in the second temporal moment. The model has good internal consistency (values $\geq .70$ ), except for the Magic dimension, at moment 1 (.68) and $2(.67)$ and the Marginal dimension (.67) at moment 2; as well as good composite reliability (most values $\geq .70$ ), except for the Magic dimension, at moment 1 (.69) and 2 (.67), and the Marginal dimension (.67) at moment 2. Finally, with regard to discriminant validity, it is also found that the model presents adequate values, with the exception of $\mathrm{AVE}_{\text {memory }}=.39$, lower than $\mathrm{r}^{2}$ memory-magic $=.42$, for the first time; and for the second time, $\mathrm{AVE}_{\text {control }}=.52$, less than $\mathrm{r}_{\text {fear-control }}^{2}=.58 ; \mathrm{AVE}_{\text {magic }}=.41$, less than $\mathrm{r}_{\text {fear-magic }}^{2}=.53$; and $\mathrm{AVE}_{\text {marginal }}=.41$, less than $\mathrm{r}^{2}$ fear-magic $=.56, \mathrm{r}_{\text {fear-magic }}^{2}=.45$ and $\mathrm{r}_{\text {fear-magic }}^{2}=.46$.

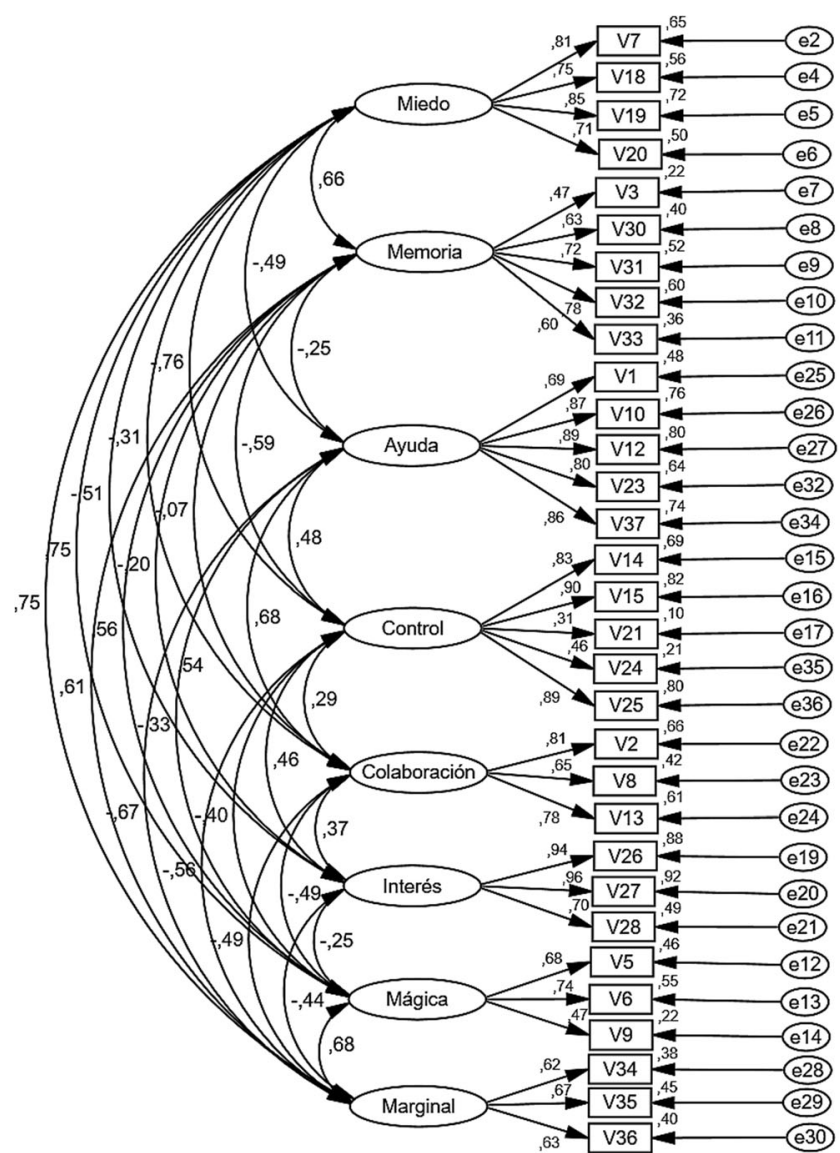

Fig. 3 Standardized individual parameters of the VSABTH-C for the sample at moment 2 (right)

\section{Invariance Analysis}

According to the procedures adopted in the methodology, the measurement model proved to be invariant over time and between genders, as indicated by the values reflected in Table 4. In other words, the results indicate that the same factors are found in each group, and each of them is associated with the same set of items (configural invariance); the same significance is found, both for the time moments and for the gender (metric invariance); that the comparison of latent and observable averages was valid across time and gender (scalar invariance); and, that group differences are only due to differences in factors (residual invariance) (Chen, 2007; Cheung and Rensvold, 2002), procedures similar to those put in place by other authors (Monteiro et al., 2018; Monteiro et al., 2019).

\section{Discussion}

The main objective of this study was to analyze the factorial structure of VSABTH-C, applied for the first time in online 
Table 2 Descriptive analysis of the responses to the VSABTH-C items

\begin{tabular}{|c|c|c|c|}
\hline \multirow[t]{2}{*}{ Factors } & \multirow[t]{2}{*}{ Items } & \multicolumn{2}{|l|}{$M(S D)$} \\
\hline & & Moment 1 & Moment 2 \\
\hline \multirow[t]{4}{*}{ Fear } & V7. I believe that under hypnosis the person is an automaton at the mercy of the hypnotist. & $2.18(1.32)$ & $2.37(1.43)$ \\
\hline & V18. I'm afraid I'll get "hooked" in a hypnotic trance. & $2.15(1.34)$ & $2.34(1.45)$ \\
\hline & V19. I believe that under hypnosis one can lose control of oneself. & $2.50(1.44)$ & $2.59(1.47)$ \\
\hline & V20. I think hypnosis can be dangerous. & $2.40(1.38)$ & $2.55(1.42)$ \\
\hline \multirow[t]{5}{*}{ Memory } & V3. You need to be in a hypnotic trance to achieve the goals of the intervention. & $3.56(1.49)$ & $3.53(1.50)$ \\
\hline & V30. What is remembered under hypnosis is the truth. & $2.80(1.28)$ & $2.82(1.33)$ \\
\hline & V31. It's impossible to lie under hypnosis, even if the hypnotized person wants to. & $2.58(1.38)$ & $2.67(1.34)$ \\
\hline & V32. One way to confirm that an event occurred is for the person to remember it under hypnosis. & $2.98(1.52)$ & $2.99(1.48)$ \\
\hline & V33. Hypnosis is a state of trance. & $3.61(1.54)$ & $3.53(1.49)$ \\
\hline \multirow[t]{5}{*}{ Help } & V1. Hypnosis can be a great help to others. & $5.02(1.00)$ & $4.92(1.11)$ \\
\hline & V10. Hypnosis can be very helpful in improving the effects of the treatments to which it is attached. & $4.74(1.11)$ & $4.69(1.20)$ \\
\hline & V12. Hypnosis is a supplement or tool to help psychological therapies. & $5.04(1.04)$ & $5.03(1.11)$ \\
\hline & V23. Hypnosis is a facilitator of therapeutic outcomes. & $4.64(1.13)$ & $4.59(1.24)$ \\
\hline & V37. Hypnosis is a supplement or tool to help medical therapies. & $4.97(1.18)$ & $4.93(1.21)$ \\
\hline \multirow[t]{5}{*}{ Control } & V14. The hypnotized person can leave the hypnosis whenever he wants. & $3.92(1.53)$ & $3.86(1.54)$ \\
\hline & V15. Under hypnosis the person retains his will to do what he wants. & $4.15(1.56)$ & $4.08(1.52)$ \\
\hline & V21. Everything that happens under hypnosis is caused by the hypnotized person. & $3.31(1.32)$ & $3.14(1.29)$ \\
\hline & V24. If the person is against a suggestion, he can ignore it completely. & $4.46(1.41)$ & $4.26(1.45)$ \\
\hline & V25. The hypnotized person maintains control over himself. & $4.15(1.40)$ & $4.09(1.41)$ \\
\hline \multirow[t]{3}{*}{ Collaboration } & V2. Hypnosis involves a cooperative effort between the hypnotist and the client. & $5.31(.86)$ & $5.28(.91)$ \\
\hline & V8. Hypnosis requires effort on the part of the hypnotized person. & $4.63(1.22)$ & $4.79(1.12)$ \\
\hline & V13. To hypnotize someone, your collaboration is needed. & $5.38(.90)$ & $5.39(.96)$ \\
\hline \multirow[t]{3}{*}{ Interest } & V26. I'd like to be hypnotized. & $4.46(1.62)$ & $4.32(1.65)$ \\
\hline & V27. I'd let myself be hypnotized if that were the case. & $4.69(1.50)$ & $4.45(1.61)$ \\
\hline & V28. I'd like to be very hypnotized. & $3.64(1.69)$ & $3.59(1.62)$ \\
\hline \multirow[t]{3}{*}{ Magic } & V5. Under hypnosis you can achieve things without any effort on the part of the person. & $2.30(1.30)$ & $2.29(1.32)$ \\
\hline & V6. Hypnosis can be a magical solution to the problems of the hypnotized person. & $1.85(1.17)$ & $1.95(1.22)$ \\
\hline & V9. Hypnosis is all that would be needed to treat most problems. & $2.04(1.09)$ & $2.19(1.17)$ \\
\hline \multirow[t]{3}{*}{ Marginal } & V34. Hypnosis takes place outside of scientific research. & $2.32(1.53)$ & $2.38(1.29)$ \\
\hline & $\begin{array}{l}\text { V35. In general, some of the fundamental characteristics of highly hypnotized people } \\
\text { would be credulity, ignorance and psychological dependence. }\end{array}$ & $2.29(1.45)$ & $2.30(1.43)$ \\
\hline & V36. The hypnotized person is dissociated. & $2.57(1.37)$ & $2.55(1.28)$ \\
\hline
\end{tabular}

version, starting from the exploratory and confirmatory analyses carried out so far in previous studies. In addition, internal consistency, convergent and discriminant validity as well as invariance analysis over time and between genders were also analyzed.

The results showed that the factor structures found so far (Carvalho et al., 2007; Capafons et al., 2008; Green et al., 2012; Capafons et al., 2015) did not fit the data well, compared to the results provided by the authors in each study. Therefore, an alternative factorial structure model was proposed based on the model by Capafons et al. (2015), eliminating a total of six items from the Scale because they showed high correlation values with several factors of the scale, that is, they were considered crossloadings. The alternative model tested (eight factors and 31 items) fit the data well, in all samples under analysis considering the values recommended in literature (Byrne, 2010; Hair et al., 2014; Marsh, Hau \& Wen, 2004). In addition, the model revealed, for most factors, adequate convergent validity values (except for Memory, Magic and Marginal, with values close to the cut-off points), indicating that most items are strongly associated with their respective factors (Hair et al., 2014). In the case of the Memory, Magic and Marginal factors, not reaching the established cut-off values could indicate, beforehand, that the items do not show a strong association with these factors. However, the factor weights showed indexes higher than .47 and statistically significant for their corresponding factor. In addition to not showing cross weights or high residual values, this, according to Hair et al., (2014), represents an adequate 
Table 3 Convergent validity, discriminant validity, extracted mean variance and internal consistency for the sample at moments 1 and 2

\begin{tabular}{|c|c|c|c|c|c|c|c|c|c|c|c|}
\hline Model & AVE & $\alpha$ & $\mathrm{CR}$ & $\mathrm{FE}$ & MEM & $\mathrm{HE}$ & $\mathrm{CON}$ & $\mathrm{COL}$ & INT & MAG & MAR \\
\hline \multicolumn{12}{|c|}{ Moment 1} \\
\hline $\mathrm{FE}$ & .64 & .88 & .88 & 1 & & & & & & & \\
\hline MEM & .39 & .75 & .76 & .45 & 1 & & & & & & \\
\hline $\mathrm{HE}$ & .66 & .91 & .91 & .12 & .00 & 1 & & & & & \\
\hline $\mathrm{CON}$ & .49 & .79 & .81 & .45 & .18 & .30 & 1 & & & & \\
\hline $\mathrm{COL}$ & .53 & .76 & .77 & .03 & .00 & .46 & .18 & 1 & & & \\
\hline INT & .75 & .89 & .90 & .20 & .02 & .26 & .18 & .15 & 1 & & \\
\hline MAG & .44 & .68 & .69 & .41 & .42 & .02 & .06 & .06 & .04 & 1 & \\
\hline MAR & .45 & .70 & .71 & .44 & .29 & .31 & .24 & .15 & .10 & .32 & 1 \\
\hline \multicolumn{12}{|c|}{ Moment 2} \\
\hline $\mathrm{FE}$ & .61 & .86 & .86 & 1 & & & & & & & \\
\hline MEM & .42 & .77 & .78 & .43 & 1 & & & & & & \\
\hline $\mathrm{HE}$ & .68 & .91 & .91 & .24 & .06 & 1 & & & & & \\
\hline $\mathrm{CON}$ & .52 & .81 & .83 & .58 & .35 & .23 & 1 & & & & \\
\hline $\mathrm{COL}$ & .56 & .78 & .75 & .09 & .00 & .46 & .08 & 1 & & & \\
\hline INT & .76 & .90 & .89 & .26 & .04 & .29 & .21 & .14 & 1 & & \\
\hline MAG & .41 & .67 & .67 & .53 & .31 & .11 & .16 & .24 & .06 & 1 & \\
\hline MAR & .41 & .67 & .67 & .56 & .37 & .45 & .31 & .24 & .19 & .46 & 1 \\
\hline
\end{tabular}

Note: $\mathrm{AVE}=$ average variance extracted; $\alpha=$ Cronbach's Alpha; $\mathrm{CR}=$ composite reliability; $\mathrm{FE}=$ Fear; $\mathrm{MEM}=$ Memory; $\mathrm{HE}=$ Help $; \mathrm{CON}=$ Control; $\mathrm{COL}=$ Collaboration; $\mathrm{INT}=$ Interest; $\mathrm{MAG}=$ Magic; $\mathrm{MAR}=$ Marginal convergent validity criterion. On the other hand, the model also showed good composite reliability, except for the Magic and Marginal factors; as well as adequate discriminant validity, except for the Memory, Control, Magic and Marginal factors because, in these cases, the convergent validity values turned out to be less than the squares of the correlations of the latent variables, which may indicate that, in some cases, it is difficult to differentiate between these factors (Hair et al., 2014).

On the other hand, with respect to the multi-group analysis, none of the studies carried out so far showed evidence that indicated the invariance of the models presented, despite being a crucial aspect in the development and use of psychometric instruments (Cheung \& Rensvold, 2002; Sass, 2011). Following the recommendations of experts in the field (Byrne, 2010; Chen, 2007; Cheung \& Rensvold, 2002), it can be stated that the measurement model presented here proved to be invariant over time as well as across gender. Specifically, following Chen (2007) the results showed that the same numbers of factors were found in the different groups, both at different time points (moment 1 and moment 2 ) and in men and women (configural invariance). In addition,
Table 4 Indexes of goodness of fit of the measures of longitudinal invariance and by gender

\begin{tabular}{lccccccccc}
\hline Models & \multicolumn{1}{l}{$\chi^{2}$} & $d f$ & $p$ & CFI & $\Delta$ CFI & SRMR & $\Delta$ SRMR & RMSEA & $\Delta$ RMSEA \\
\hline \multicolumn{2}{l}{ Moment1-Moment2 } & & & & & & & & \\
CI & 2105.53 & 812 & $<.001$ & .915 & - & .068 & - & .042 & - \\
MI & 2131.42 & 835 & $<.001$ & .915 & .000 & .069 & .001 & .042 & .000 \\
SI & 2184.60 & 871 & $<.001$ & .913 & .002 & .078 & -.010 & .041 & .001 \\
RI & 2284.52 & 902 & $<.001$ & .909 & .005 & .078 & -.010 & .041 & .001 \\
\multicolumn{2}{l}{ Male-Female } & & & & & & & & \\
CI & 1812.03 & 812 & $<.001$ & .916 & - & .059 & - & .042 & - \\
MI & 1841.23 & 835 & $<.001$ & .915 & .001 & .059 & .000 & .041 & .001 \\
SI & 1900.72 & 871 & $<.001$ & .913 & .003 & .065 & -.006 & .041 & .001 \\
RI & 2031.59 & 902 & $<.001$ & .905 & .011 & .065 & -.006 & .042 & .000 \\
\hline
\end{tabular}

Note: $\chi^{2}=$ chi - square $; \mathrm{df}=$ degrees of freedom; $\mathrm{CFI}=$ comparative fit index; $\Delta \mathrm{CFI}=$ differences in comparative fit index values; $S R M R=$ standardized root mean square residual; $\triangle \mathrm{SRMR}=$ differences in standardized root mean square residual values; RMSEA = root mean square error of approximation; $\triangle \mathrm{RMSEA}=$ differences in root mean square error of approximation values; $\mathrm{CI}=$ configural invariance; $\mathrm{MI}=$ metric invariance; $\mathrm{SI}=\mathrm{scalar}$ invariance; $\mathrm{RI}=$ residual invariance 
the items showed the same association with the factors, regardless of the characteristics of the samples (metric invariance) and the perception of the Scale items was also similar for each of the groups (scalar invariance). That is, the theoretical dimensions underlying the measurement model were perceived in the same way by men and women, as well as after some time in the evaluation (Sass, 2011). Finally, the differences found between the groups were due to differences in factors (residual invariance). Therefore, it can be concluded that the model showed evidence of being invariant over time and by gender, since it met the reference values for the four types of invariance, including residual invariance, whose scope is difficult to meet, especially in the field of social sciences (Byrne, 2010; Cheung \& Rensvold, 2002).

Taking into account the results obtained, it would be interesting to consider the option of optimizing the items that are eliminated, since with their current formulation they pose a problem for the adjustment of the model. It is possible that, with its current wording, the participants may not be able to fully understand what they refer to. Addressing the optimization proposal would avoid the loss of relevant information that some of these items have with respect to the content of the Scale.

About limitations, firstly about the information regarding the participants' previous hypnosis experience, which was collected as merely descriptive information. Since it did not work directly with the beliefs and attitudes of the participants, but rather collected the results in order to analyze the psychometric properties of the questionnaire, this information about the previous experience was not included in the study other than to describe the participants. On the other hand, it is worth noting the small problems encountered in some factors, especially Magic and Marginal, which presented small problems of convergent validity, composite reliability and discriminant validity. Likewise, we should also point out the sample difference by gender, given that there were practically half as many male as female participants. Although it did not negatively affect gender invariance, having a larger sample of men would have allowed the existing gender differences to be more deeply explored.

In short, it can be stated that the model obtained presents a satisfactory fit to all the data of the participants under study, in comparison with other previous studies in which the psychometric properties of the Scale are analyzed, and in which the factorial models did not show adequate adjustment rates. According to this information we can therefore conclude that the model for VSABTH-C, with eight factors and 31 items, is an adequate measurement tool to evaluate attitudes and beliefs about hypnosis; as well as it shows evidence of validity, reliability and invariance across time and gender. In other words, it would be a valid, reliable and sensitive tool for assessing changes in clients' attitudes and beliefs over time and gender.
Based on this information, future studies could be directed, as mentioned above, to optimize the items that have been eliminated, given their importance, and subject them to a new psychometric review, since the validation of a questionnaire is always a continuous process. Also, to adapt the Scale to other countries, as is already being done, as well as to compare the scores and profiles obtained, prior to an analysis of cultural invariance. It would also be interesting to relate to other similar scales (Green et al., 2012) or test the invariance based on other characteristics. To the extent that attitudes and beliefs may predict success in a hypnosis intervention program, a critical issue would be to determine the predictive value of the Scale on the outcomes of the intervention, as well as to make comparisons with other estimated measures, such as hypnotic suggestibility or motivation. All of this is done with the intention of adapting the set of techniques used, so that patients can extract the greatest possible benefit, which is, in the end, the priority objective.

\section{Compliance with Ethical Standards}

Conflict of Interest The authors declare that they have no conflict of interest.

Ethical Approval and Informed Consent The work was approved by the Ethics Committee of the University of Malaga No. 19-2015-H. In addition, the guidelines of the Declaration of Helsinki (revision of 2013), the recommendations of Good Clinical Practice of the EEC (document 111/ $3976 / 88$ of July 1990) and the current Spanish legal regulations governing clinical research in humans (Royal Decree 561/1993) were followed. In addition, the Informed Consent appears in the Conditions accepted when registering on the platform MenPas, which are made in accordance with the provisions of Law 15/1999 of 13 December on the Protection of Personal Data (LOPD), the user registered on the platform authorizes that the data provided will be incorporated and processed in the electronic file owned MenPas.

\section{References}

Alarcón, A., \& Capafons, A. (2006). El modelo de Valencia de hipnosis despierta: ¿técnicas nuevas o técnicas innovadoras? Papeles del Psicólogo/Psychologist Papers, 27(2), 70-78.

Barber, T. X. (1969). Hypnosis: A scientific approach. New York, NY: Van Nostrand Reinchold.

Byrne, B. (2010). Structural equation modeling with AMOS. Basic concepts, applications, and programming. New York, NY: Taylor \& Francis Group, LLC.

Capafons, A. (1999). La hipnosis despierta setenta y cuatro años después. Anales de Psicologia/Annals of Psychology, 15(1), 77-78.

Capafons, A. (2012). Hipnosis: Segunda edición ampliada y revisada. Madrid, SP: Síntesis.

Capafons, A., Alarcón, A., Cabañas, S., \& Espejo, B. (2003). Análisis factorial exploratorio y propiedades psicométricas del cuestionario de creencias y actitudes hacia la hipnosis-cliente. Psicothema, 15(1), 143-147.

Capafons, A., Cabañas, S., Alarcón, A., Espejo, B., Mendoza, M. E., Chaves, J. F., \& Monje, A. (2005). Effects of different types of 
preparatory information on attitudes toward hypnosis. Contemporary Hypnosis, 22(2), 67-76. https://doi.org/10.1002/ch. 25.

Capafons, A., Cabañas, S., Espejo, B., \& Cardeña, E. (2004). Confirmatory factor analysis of the Valencia scale on attitudes and beliefs toward hypnosis: An international study. International Journal of Clinical and Experimental Hypnosis, 52(4), 413-433. https://doi.org/10.1080/00207140490888432.

Capafons, A., \& Mazzoni, G. (2005). ¿Es lo peligroso de la hipnosis el hipnoterapeuta?: Hipnosis y falsos recuerdos. Papeles del Psicólogo/Psychologist Papers, 25(89), 27-38.

Capafons, A., \& Mendoza, E. (2010). Waking hypnosis in clínical practice. En S. J. Lynn, J. W. Rhue, \& I. Kirsch (Eds.), Handbook of clinical hypnosis ( $2^{\mathrm{a}}$ ed.) (pp. 293-317). Washington, D.C.: American Psychological Association.

Capafons, A., Mendoza, E., Espejo, B., Green, J. P., Lopes-Pires, C., Selma, M. L., et al. (2008). Attitudes and beliefs about hypnosis: A multicultural study. Contemporary Hypnosis, 25, 141-155. https://doi.org/10.1002/ch.359.

Capafons, A., Morales, C., Espejo, B., \& Cabañas, S. (2006). Análisis factorial exploratorio y propiedades psicométricas de la escala de Valencia de actitudes y creencias hacia la hipnosis, versión terapeuta. Psicothema, 18(4), 810-815. https://doi.org/10.1002/ch. 332.

Capafons, A., Suárez-Rodríguez, J. M., \& Selma, M. L. (2015). Análisis factorial confirmatorio de la escala valencia de actitudes y creencias hacia la hipnosis (versión cliente revisada) en una muestra española. Anales de Psicología/Annals of Psychology, 31(1), 84-95. https:// doi.org/10.1080/00207144.2018.1396107.

Carvalho, C., Capafons, A., Kirsch, I., Espejo, B., Mazzoni, G., \& Leal, I. (2007). Factorial analysis and psychometric properties of the revised Valencia Scale of attitudes and beliefs towards hypnosis - Client version. Contemporary Hypnosis, 24(2), 76-85. https://doi.org/10. 1002/ch.332.

Chen, F. F. (2007). Sensitivity of goodness of fit indexes to lack of measurement invariance. Structural Equation Modeling: A Multidisciplinary Journal, 14(3), 464-504. https://doi.org/10.1080/ 10705510701301834.

Cheung, G., \& Rensvold, R. (2002). Evaluating goodness-of-fit indexes for testing measurement invariance. Structural Equation Modeling, 9(2), 233-255. https://doi.org/10.1207/s15328007sem0902 5.

Cronbach, L. J. (1951). Coefficient alfa and the internal structure of test. Psychometrika, 16(3), 297-334.

González-Ruíz, S. L., Domínguez-Alfonso, R., Chica-Merino, E., Pastrana-Brincones, J. L., \& Hernández-Mendo, A. (2018). Una plataforma virtual para la evaluación e investigación on-line: Menpas. Cuadernos de Psicología del Deporte, 18(3), 26-48.

González-Ruíz, S. L., Hernández-Mendo, A., \& Pastrana-Brincones, J. L. (2010). Herramienta software para la evaluación psicosocial de deportistas y entornos deportivos. Lecturas: EF y Deportes. Revista Digital/Readings: PE and Sports. Digital Journal, 15(144) septiembre. Obtenido 17 de septiembre de 2019: http://www. efdeportes.com/efd144/evaluacion-psicosocial-de-deportistas.htm.

Green, J. P. (2003). Beliefs about hypnosis: Popular beliefs, misconceptions, and the importance of experience. International Journal of Clinical and Experimental Hypnosis, 51(4), 369-381. https://doi. org/10.1076/iceh.51.4.369.16408.

Green, J. P., Houts, C. R., \& Capafons, A. (2012). Attitudes about hypnosis factor analyzing the VSABTH-C with an American sample. American Journal of Clinical Hypnosis, 54(3), 167-178. https://doi. org/10.1080/00029157.2011.616823.

Hair, J., Black, W., Babin, B., \& Anderson, R. (2014). Multivariate Data Analysis. New Jersey, NJ: Pearson Educational, Inc..

Keller, R. F. (1996). Hypnosis belief survey. Psychological Hypnosis, 5 , 8-9.
Kirsch, I. (1991). The social learning theory of hypnosis. S. Lynn and Rhue (Eds), Theories of hypnosis: Current models and perspectives (pp 439-466) New York, NY Guilford. https://doi.org/10.1080/ 00029157.1994 .10403122 .

Kirsch, I. (2000). The response set theory of hypnosis. American Journal of Clinical Hypnosis, 42(3-4), 274-293.

Kline, R. (2011). Principles and practice of structural equation modeling. New York, NY: The Guilford Press.

Kline, R. B. (2016). Methodology in the social sciences. Principles and practice of structural equation modeling (4th ed.). New York, NY: The Guilford Press.

Lynn, S. J., \& Kirsch, I. (2004). Teoría de hipnosis. Papeles del Psicólogo/ Psychologist Papers, 89, 9-15.

Marsh, H. W., Hau, K.-T., \& Wen, Z. (2004). In search of golden rules: Comment on hypothesis-testing approaches to cutoff values for fit indexes and dangers in overgeneralizing $\mathrm{Hu} \&$ Bentler's findings (1999). Structural Equation Modeling: A Multidisciplinary Journal, 11, 320-341. https://doi.org/10.1207/ s15328007sem1103_2.

McConkey, K. M. (1986). Opinions about hypnosis and self-hypnosis before and after hypnotic testing. International Journal of Clinical and Experimental Hypnosis, 34(4), 311-319. https://doi.org/10. 1080/00207148608406996.

Mendoza, M. E., \& Capafons, A. (2009). Eficacia de la hipnosis clínica: resumen de su evidencia empírica. Papeles del Psicólogo/ Psychologist Papers, 30(2), 98-116.

Mendoza, M. E., Capafons, A., \& Jensen, M. P. (2017). Hypnosis attitudes: Treatment effects and associations with symptoms in individuals with cancer. American Journal of Clinical Hypnosis, 60(1), 50 67. https://doi.org/10.1080/00029157.2017.1300570.

Meredith, W. (1993). Measurement invariance, factor analysis and factorial invariance. Psychometrika, 58, 525-543. https://doi.org/10. 1007/bf02294825.

Molina-del-Peral, J. A., Mendoza, M. E., Capafons, A., \& LlanesBasulto, Y. (2016). Hipnosis clínica: Evaluación de su eficacia y calidad de la investigación en psicología. Revista del Hospital Psiquiátrico de la Habana, 13(2). http://www.revistahph.sld.cu/ 2016/Nro\%202/hipnosis\%20clinica.html.

Monteiro, D., Borrego, C., Silva, C., Moutão, J., Marinho, D. A., \& Cid, L. (2018). Motivational climate sport youth scale: Measurement invariance across gender and five different sports. Journal of Human Kinetics, 61, 249-261. https://doi.org/10.1515/hukin-20170124.

Monteiro, D., Teixeira, D. S., Vitorino, A., Moutão, J., Rodrigues, F., Machado, S., \& Cid, L. (2019). Behavioural regulation sport questionnaire: Gender and sport invariance in Portuguese atheletes. Perceptual and Motor Skills, 126(2), 323-341. https://doi.org/10. 1177/0031512519825700.

Nevitt, J., \& Hancock, G. (2001). Performance of bootstrapping approaches to model test statistics and parameter standard error estimation in structural equation modeling. Structural Equation Modeling, 8(3), 353-377. https://doi.org/10.1207/ s15328007sem0803_2.

Rodrigues, F., Pelletier, L. G., Neiva, H., Teixeira, D. S., Cid, L., \& Monteiro, D. (2019). Initial validation of the interpersonal behavior in exercise questionnaire (IBQ \& IBQ-self): Measurement invariance and latent mean differences. Current Psychology. https://doi. org/10.1007/s12144-019-00374-y.

Sass, D. (2011). Testing measurement invariance and comparing latent factor means within a confirmatory factor analysis framework. Journal of Psychoeducational Assessment, 29(4), 347-363. https:// doi.org/10.1177/0734282911406661.

Sliwinskiand, J. G., \& Elkins, R. (2013). Enhancing placebo effects: Insights from social psychology. American Journal of Clinical Hypnosis, 55, 236-248. https://doi.org/10.1080/00029157.2012. 740434. 
Spanos, N. P., Brett, P. J., Menary, E. P., \& Cross, W. P. (1987). A measure of attitudes toward hypnosis: Relationships with absorption and hypnotic susceptibility. American Journal of Clinical Hypnosis, 30(2), 139-150. https://doi.org/10.1080/00029157.1987.10404174.

Spanos, N. P., \& Chaves, J. F. (1991). History and historiography of hypnosis. En S. J. Lynn \& J. W. Rhue (Eds.), Theories of hypnosis: Current models and perspectives (pp. 43-82). New York, NY: Guilford Press. https://doi.org/10.1080/00029157.1992.10402984, 35.

Stenling, A., Ivarsson, A., Lindwall, M., \& Gucciardi, D. F. (2018). Exploring longitudinal measurement invariance and the continuum hypothesis in the Swedish version of the Behavioural regulation in sport questionnaire (BRSQ): An exploratory structural equation modeling approach. Psychology of Sport and Exercise, 36, 187196. https://doi.org/10.1016/j.psychsport.2018.03.002.

World Medical Association. (2013). World medical association declaration of Helsinki: Ethical principles for medical research involving human subjects. Journal of the American Medical Association, 310, 2191-2194. https://doi.org/10.1001/jama.2013.281053.

Worthington, R. L., \& Whittaker, T. A. (2006). Scale development research. A content análisis and recommendations for best practices. The Counselling Psychologist, 34(6), 806-838. https://doi.org/10. $1177 / 0011000006288127$.

Publisher's Note Springer Nature remains neutral with regard to jurisdictional claims in published maps and institutional affiliations. 